\title{
NOTE
}

\section{Intertidal rack-and-bag oyster farms have limited interaction with horseshoe crab activity in New Jersey, USA}

\author{
Daphne Munroe*, David Bushek, Patricia Woodruff, Lisa Calvo \\ Haskin Shellfish Research Laboratory, Rutgers University, 6959 Miller Ave., Port Norris, NJ 08349, USA
}

\begin{abstract}
Concern has been raised about the ability of horseshoe crabs Limulus polyphemus to traverse intertidal rack-and-bag oyster farms, and how farms may change shorebird foraging activity. During the 2016 horseshoe crab spawning season, experiments conducted in Delaware Bay (New Jersey, USA) assessed the ability of crabs to move among oyster farms and access landward nesting grounds, and surveyed the distribution of dislodged eggs upon which many shorebirds feed. Experiments included testing (1) for impairment of crab passage by oyster racks, (2) for differences in crab abundance among paired farm/control transects, (3) whether farms affect crab stranding rates on nesting beaches, and (4) assessing the spatial distribution of dislodged eggs along the wrack zone among farm and non-farm areas. All crabs, regardless of size, passed beneath racks $\geq 10 \mathrm{~cm}$ tall, indicating that the regulated rack height of $30.5 \mathrm{~cm}$ is abundantly precautious to allow crab movement beneath racks. Farm/control census observed 853 crabs in total, with no evidence of differing crab numbers among farmed and control transects. Only 2 of 853 $(<0.5 \%)$ crabs were obstructed by farm gear, and more crabs were present on nesting beaches inshore of farms compared to adjacent farm-free areas. The proportion of crabs flipped (stranded) at low tide within nesting habitats was constant regardless of farm presence. Dislodged eggs in the wrack zone were observed most frequently in the center of the survey area, and were not concentrated near farms, suggesting that in 2016, shorebird foraging opportunities were not coincident with farm locations.
\end{abstract}

KEY WORDS: Oyster aquaculture $\cdot$ Crassostrea virginica $\cdot$ Rack-and-bag $\cdot$ Limulus polyphemus Ecological interactions $\cdot$ Shorebird foraging

\section{INTRODUCTION}

For the first time since records have been kept, the contribution of aquaculture to global seafood supply has exceeded that of wild capture fisheries (FAO 2016). Although shellfish culture is largely viewed as an environmentally and ecologically sound industry (Shumway et al. 2003), as global production expands, the industry is faced with key challenges to ensure ecological sustainability and social acceptance. The

\footnotetext{
*Corresponding author: dmunroe@hsrl.rutgers.edu
}

ways in which molluscan aquaculture interacts with fundamental ecosystem processes such as particle depletion, nutrient cycling, and benthic-pelagic coupling has been relatively well studied (Newell 2004, Dumbauld et al. 2009, Rose et al. 2015); however, central to sustainability and acceptance is also understanding the nature of the interaction among farms and wildlife such as birds and mammals that may use habitat near to or occupied by farms. Studies that have examined the ways that molluscan farms inter-

() The authors 2017. Open Access under Creative Commons by Attribution Licence. Use, distribution and reproduction are unrestricted. Authors and original publication must be credited. 


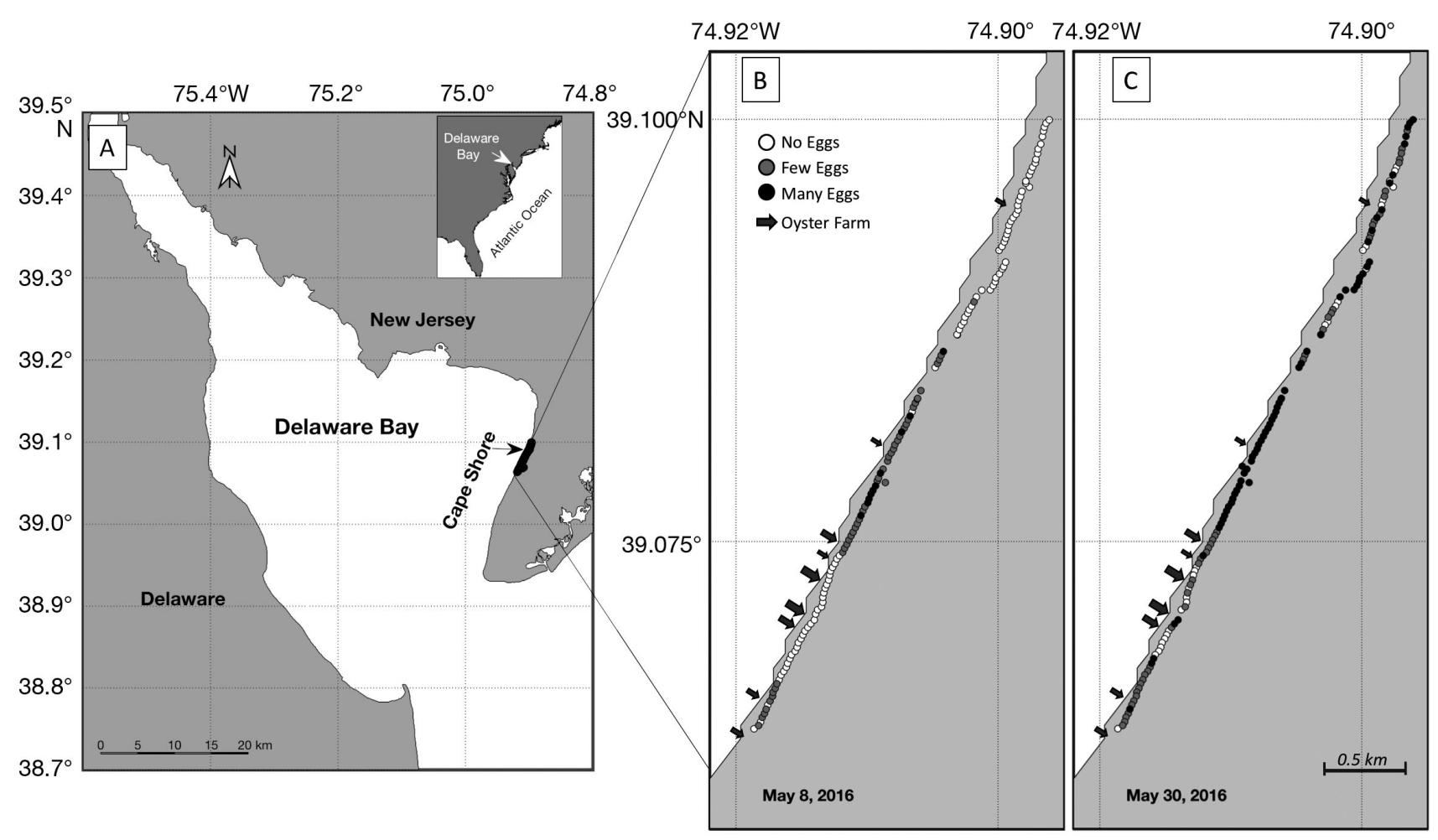

Fig. 1. (A) Study area in Delaware Bay, USA, with the Cape Shore region noted in black. Zoomed-in panels show the distributions of washed up horseshoe crab Limulus polyphemus eggs on (B) 8 May and (C) 30 May 2016 within the Cape Shore region relative to farm locations; arrows denote farm locations, and arrow size scales with the relative farm footprint

act with local avian populations provide examples of mixed interactions (Roycroft et al. 2004, Godet et al. 2009, Žydelis et al. 2009), leaving the question unable to be generalized broadly across species, habitats, and culture practices.

Shellfish aquaculture in the Cape Shore region of New Jersey (USA) has a long history as a local food production system (Ford 1997). Eastern oyster Crassostrea virginica production declined sharply following the appearance of Multinucleated Sphere X, more commonly known as MSX disease (caused by Haplosporidium nelsoni) in 1957 and the more recent establishment of perkinsosis (caused by Perkinsus marinus) (Ford 1997). Advances in hatchery and production methods as well as the development of disease-resistant stocks and triploid technology (Dégremont et al. 2015) have revived the industry. Today, an annual production of approximately 1.8 million market-sized aquacultured oysters is primarily carried out on intertidal farms in the Cape Shore, encompassing 10 acres ( $4.05 \mathrm{ha}$ ) of actively farmed bottom (Calvo 2017).

Horseshoe crabs Limulus polyphemus are an iconic and ecologically important species in the Delaware Bay area. Hundreds of thousands come ashore dur- ing spring to mate and lay eggs along sandy beaches of the New Jersey and Delaware coastline (Smith et al. 2002, 2017). Approximately $5 \%$ of the total shoreline baywide that has been categorized as suitable for crab spawning (Lathrop et al. 2006) is also home to rack-and-bag oyster farming. These activities occur in the Cape Shore region, where farmers grow oysters in specialized cultivation bags on top of short metal racks. Recently, horseshoe crab biologists with a history of studying this region have indicated that most of this area is no longer suitable habitat due to shoreline erosion following recent changes in sea level (Loveland \& Botton 2015). Variations of this cultivation method have occurred along this region for more than a century (Ford 1997). An important migratory food source for red knots are lipid-rich horseshoe crab eggs (Haramis et al. 2007) that are deposited on beaches along the migratory route by mating crabs during the birds' spring northward migration, typically in May of each year (Castro \& Myers 1993, Botton et al. 1994). The eggs become available to the transitory bird flocks when they are exhumed from nests by sediment disturbance such as crab burrowing and wave action (Kraeuter \& Fegley 1994, Smith 2007) and become concentrated in the 
upper intertidal zone by wave action in the swash zone as the tide rises (Nordstrom et al. 2006).

The rufa subspecies of the red knot Calidris canutus is a medium-bodied shorebird that breeds in the Canadian Arctic and winters in parts of the southern USA, the Caribbean, and South America (Morrison \& Hobson 2004). Red knots migrate between wintering and breeding grounds using stopover areas along the Atlantic coast of the USA, one of which is the shore of the Delaware Bay (Clark et al. 1993, Botton et al. 1994; Fig. 1A). Effective 12 January 2015, the red knot was designated under the US Endangered Species Act as 'Threatened' in the USA by the US Fish and Wildlife Service; Canada listed it as Endangered in 2007.

Concern has recently been raised about the ability of horseshoe crabs to traverse intertidal rack-andbag oyster farms, and how farms may change shorebird foraging activity leading to the implementation of precautionary risk-averse conservation measures until additional information is obtained (Walsh et al. 2016). During the spawning season in 2016, we conducted a series of experiments to assess the ecological interactions among intertidal rack-and-bag oyster farms and horseshoe crabs and shorebird feeding opportunities. These included tests of whether horseshoe crabs are impinged by farm gear or alter their movement in, around, and among the oyster farms as they make their way to mate and spawn on nesting beaches, and a census of the spatial distribution of washed up eggs upon which red knots feed.

\section{MATERIALS AND METHODS}

All experiments were conducted in the Cape Shore region along the New Jersey side of the southern Delaware Bay (Fig. 1A) during late spring through early summer of 2016 (mid-April through late June). The study region is characterized by extensive mudflats that are exposed at low tide, and sloping sand beaches bordered by salt marsh at the upper intertidal. Tides in the Delaware Bay are semidiurnal, with a mean range of $1.6 \mathrm{~m}$.

\section{Testing rack heights for impairment of crab passage}

During a daytime low tide, oyster racks were set at 4 heights above the surface of the sand: 7.5, 10.2, 15.2 , and $30.5 \mathrm{~cm}$. A range of 10 to 20 male horseshoe crabs ranging in prosoma width from 17.5 to $23.0 \mathrm{~cm}$ were collected from adjacent/nearby sloughs and placed right side up approximately $1 \mathrm{~m}$ from and facing toward the rack, then observed as they walked beneath the rack. The prosoma width and success or failure of each crab to pass beneath the rack was recorded. Crabs that arrested movement as they physically came into contact with the racks were scored as having impaired movement.

\section{Repeated transects to test if crabs avoid farms}

Paired farm/control transects were established at each of 2 active oyster farms on the Cape Shore ( $\mathrm{n}=$ 4 transects total). Each pair included 1 transect that intersected the farm, and 1 parallel control transect $20 \mathrm{~m}$ from the farm that passed through adjacent unfarmed intertidal habitat (Fig. 2). Each transect spanned a $1 \mathrm{~m}$ wide area perpendicular to the high tide line, and covered a zone inshore of the farm area (Zone 1) and through the farm (Zone 2) (Fig. 2). Transect lengths at each of the farms were unequal due to the nature of the mudflats on which they were located; they measured 190 and $138 \mathrm{~m}$ in total length (Farm A and B, respectively), with Zone 1 spanning the inshore 128 and $93 \mathrm{~m}$ of each (Farm A and B, respectively). The paired transects were surveyed a

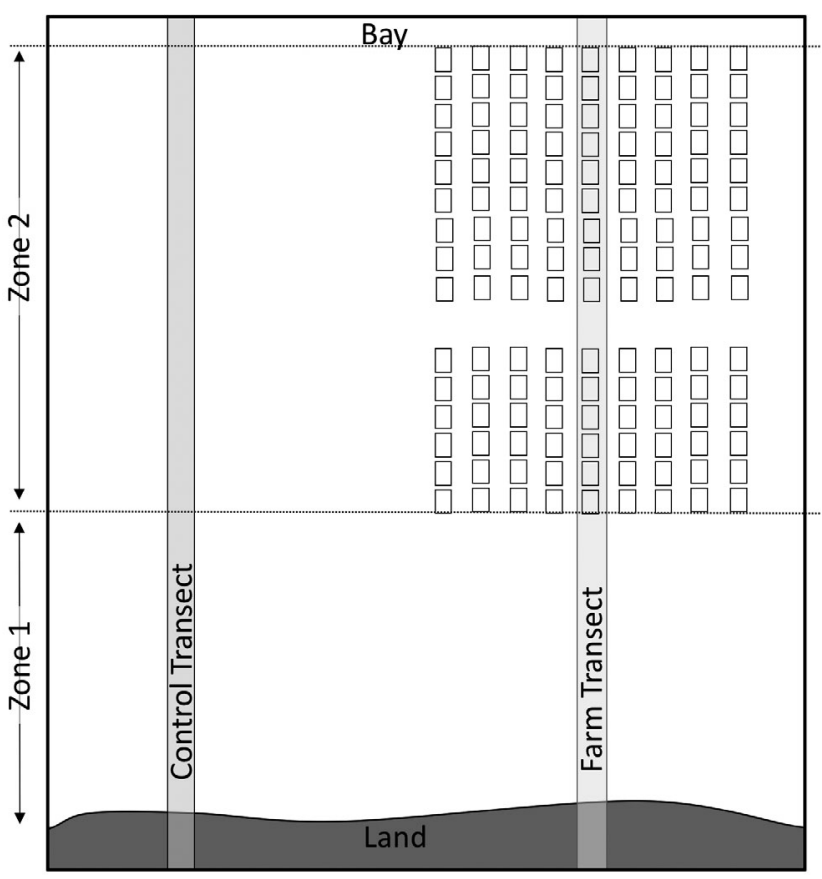

Fig. 2. Schematic layout of paired oyster farm and control transects. Transects at each of the farms were unequal; they measured 190 and $138 \mathrm{~m}$ in total length (Farms A and B, respectively), with Zone 1 spanning the inshore 128 and $93 \mathrm{~m}$ of each, respectively. Rectangles indicate individual oyster racks 
total of 10 times during daytime low tides between 29 April and 15 June 2016. Location and activity of all crabs encountered (observed visually) along each transect were recorded, and all crabs whose mobility was impaired by a rack (e.g. crabs that were trapped, caught, or impinged) were noted.

Data were non-normally distributed, thus a nonparametric Wilcoxon signed rank test was performed to test for differences in the abundance of crabs observed on control versus farm transects. Absolute values of crab observations varied greatly over the course of the study due to seasonal spawning immigration and emigration; therefore, standardization of each survey was performed by summing paired transect counts for each survey and then calculating the fraction of the total that was observed on the farm. The fraction observed on the farm transect was then analyzed using a mixed model analysis of variance in which zone was nested within farm site to assess the influence of zone.

\section{Nesting beach census}

Three adjacent upper beach segments spanning approximately $91 \mathrm{~m}$ (150 yards) parallel to the shoreline were surveyed on 16 nights bracketing horseshoe crab spawning peaks around full and new moons between 22 April and 22 June 2016. The central segment was inshore of an active oyster farm, whereas the 2 segments on either side were not. Surveys were conducted at night $3 \mathrm{~h}$ after high tide to enumerate stranded crabs. All live crabs in the upper beach spawning habitat were counted and recorded along with their condition: flipped on their back (stranded) or right side up. The fractions of crabs flipped at farm and non-farm segments were compared using repeated measures analysis of variance.

\section{Spatial survey of washed up egg distribution}

Two photographic censuses were performed overnight on 8 and 30 May 2016, to document the distribution of horseshoe crab eggs washed up near the high tide line where red knot foraging is concentrated (Burger et al. 1977, 1997, Botton et al. 1994). The upper intertidal along the Cape Shore region (Fig. 1A) was divided evenly into 150 segments (approximately $91 \mathrm{~m}$ of shoreline per segment), and photographic samples documented a $0.5 \mathrm{~m}$ wide (alongshore) by $1 \mathrm{~m}$ (downbeach) quadrat perpendicular to the high tide line and crossing the wrack line, located randomly alongshore near the center of each segment. Each photographic quadrat was assessed for the presence of horseshoe crab eggs that had been washed up at the surface, and each quadrat was coded as having no eggs, few eggs (defined as $\leq 5 \%$ of the quadrat containing eggs), and many eggs (defined as $>5 \%$ of the quadrat containing eggs).

\section{RESULTS}

All crabs, regardless of prosoma width, were able to pass beneath racks $\geq 10 \mathrm{~cm}$ above the bottom (Fig. 3). Of the total 48 observations, 42 crabs passed beneath the racks, whilst 6 failed to transit the rack. Those 6 were among a total of 10 crabs tested at a rack height of $7.5 \mathrm{~cm}$; the other 4 were able to pass the rack at a height of $7.5 \mathrm{~cm}$. All of the 6 crabs that were unable to pass buried the front of their prosoma beneath the rack edge and stopped, but were not irreversibly stuck.

In total, we observed 853 crabs during the repeated transect surveys, with a relatively even distribution of crabs between farm and control transects (46 farm and 39 control transects at Site A, and 369 farm and 399 control transects at Site B, Table 1), both inshore

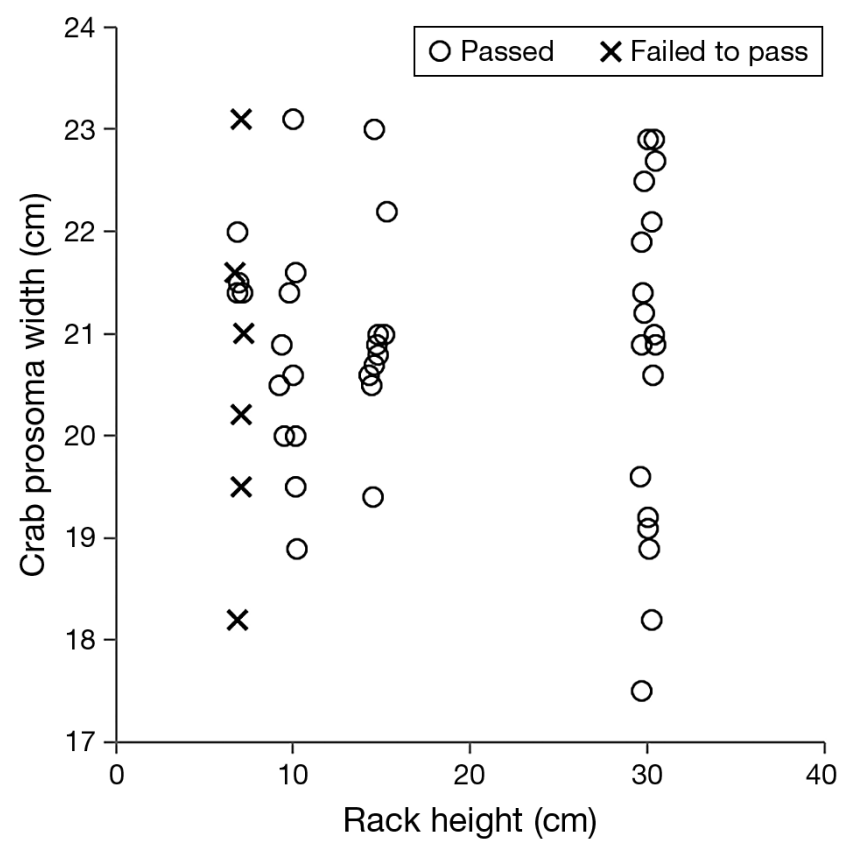

Fig. 3. Success (open circles) and failure (marked with ' $x$ ') of horseshoe crabs Limulus polyphemus to pass beneath oyster racks set to $7.5,10.2,15.2$ and $30.5 \mathrm{~cm}$ above the sediment surface. Data points represent individual crabs for each rack height and have been jittered to help illustrate the distribution 
Table 1. Total horseshoe crab Limulus polyphemus counts observed during 10 transect surveys performed periodically during daytime low tide between 29 April and 15 June 2016. See Fig. 2 for the layout of the transects

\begin{tabular}{|lrc|}
\hline & Farm A & Farm B \\
\hline Control transect & & \\
Zone 1 & 36 & 188 \\
Zone 2 & 3 & 211 \\
Farm transect & & \\
Zone 1 & 23 & 215 \\
Zone 2 & 23 & 154 \\
\hline
\end{tabular}

of farm activities (Zone 1) and within the farms (Zone 2). In total, 2 out of $853(<0.5 \%)$ crabs were observed to be obstructed by racks.

The first 2 and final farm transect surveys were removed from statistical analyses because very few crabs were observed at the beginning and end of the study (i.e. many 0 counts). We found no significant difference in the number of crabs among farm and control transects $(V=76.5, \mathrm{p}=0.3$, paired Wilcoxon signed rank test). Likewise, the fraction of crabs observed on the farm transects approximated 0.5 , and zone $(F=0.94, \mathrm{p}=0.51)$ did not significantly affect the fraction of crabs observed on the farm transects.

In total, 3527 live crabs were counted on the 3 nesting beach segments during overnight censuses, with nearly half of those $(48 \%)$ observed in the central segment inshore of the oyster farm. Segment 2 (inshore of the farm) tended to have more crabs observed during each census (Fig. 4), with the highest numbers of crabs on all 3 segments associated with full and new moons in the middle of the spawning season (Fig. 4). The fraction of flipped (stranded) crabs varied greatly among censuses; however, there was no significant difference in the fraction of flipped (stranded) crabs among farmed and nonfarmed segments (Fig. $5 ; F=15.2, \mathrm{p}=$ $0.16)$.

The amount of washed up eggs observed in the survey was relatively lower in early May, before the majority of crabs returned to spawn. Densities of crab eggs washed up at the high tide line were distributed unevenly throughout the region surveyed (Fig. 1B,C). Washed up eggs were observed most frequently in the central portion of the survey area, and were not highly concentrated in the area of farms.

\section{DISCUSSION}

Complementary experiments and surveys were conducted during the 2016 horseshoe crab spawning season to assess the ecological interactions among intertidal rack-and-bag oyster farms and horseshoe crabs and shorebird feeding opportunities. These included tests of whether horseshoe crabs become trapped by gear or alter their movement in, around, and among the oyster farms as they make their way to mate on nesting beaches, and a census of the spatial distribution of washed up eggs upon which red knots feed. All crabs, regardless of size, passed easily beneath racks positioned $\geq 10 \mathrm{~cm}$ above the bottom. This rack height corresponds with prosoma heights measured across a random selection of spawning male and female crabs ( 7.5 and $10.0 \mathrm{~cm}$, respectively) from this same region (Kraeuter \& Fegley 1994). Thus, the regulated rack height of $30.5 \mathrm{~cm}$ should be sufficiently precautious to allow crab movement beneath racks.

Repeated surveys of paired farm-control transects showed no evidence that crabs avoid or are trapped by farms as they come ashore to mate and lay eggs. The 2 farms used in this study showed a large difference in the number of crabs observed during transect surveys, with Site A being a longer transect with fewer crabs. The Cape Shore shoreline is somewhat

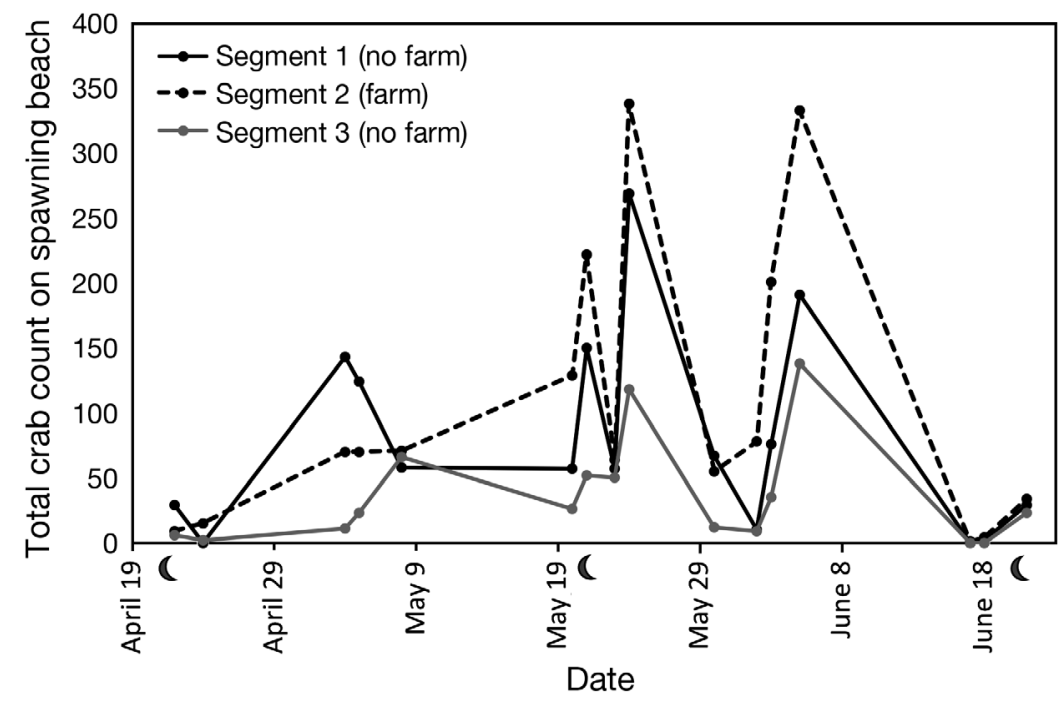

Fig. 4. Time series of total live horseshoe crabs Limulus polyphemus counted during each overnight census of nesting habitat conducted during the 2016 horseshoe crab spawning season. Solid black, dashed black, and solid grey lines show counts on Segments 1, 2, and 3, respectively. Moon symbols along the $x$-axis show the full moon events 


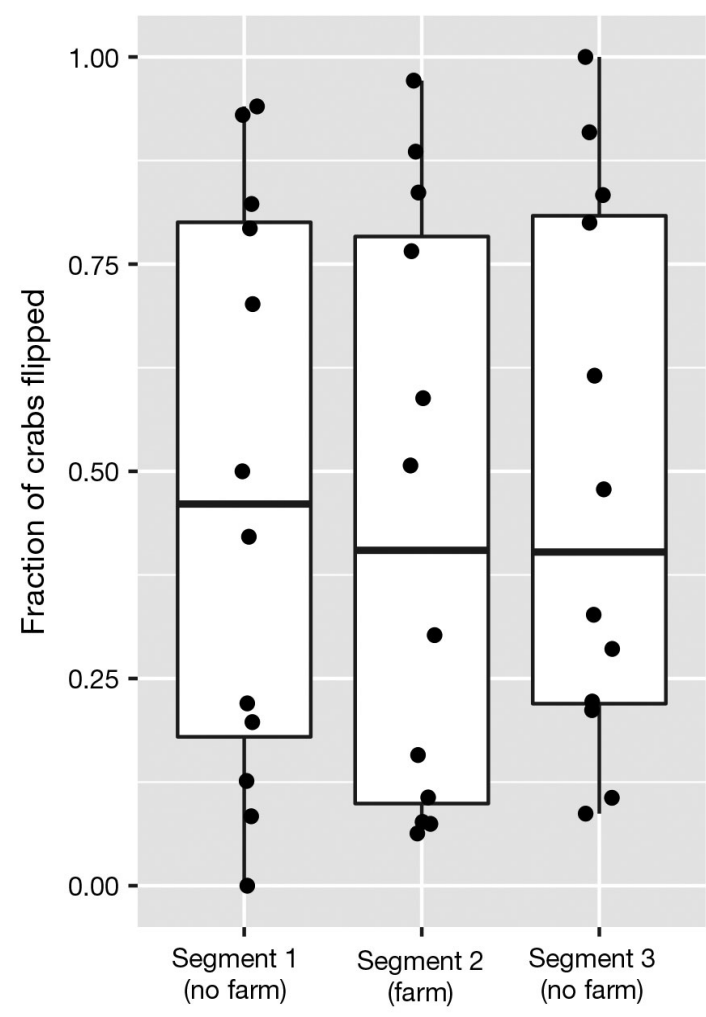

Fig. 5. Fraction of horseshoe crabs Limulus polyphemus flipped over (stranded) in the upper intertidal in each of 3 surveyed segments, with each census observation overlaid (black dots). Box plot-line: median, box: $25^{\text {th }}$ and $75^{\text {th }}$ percentile, whiskers: minimum and maximum observations

heterogeneous in the quality of crab habitat, with high-quality habitat, erosional areas, and some bulkheaded sections; the 2 farms also differed in the quality of the crab habitat near the upper intertidal. At Site A, the upper intertidal had been eroded with exposed peat, which has been shown to lead to fewer crabs returning to spawn (Botton et al. 1988). Site B was located within a section of higher quality, predominantly sandy crab habitat.

Farm gear did not alter the number of horseshoe crabs onshore on nesting beaches (Fig. 4). In fact, the trend was for more crabs to be present on nesting beaches inshore of where farming was occurring. The fraction of crabs on nesting beaches that were flipped over (stranded) varied greatly among the census walks, with a tendency for a greater fraction flipped on nights when wind and waves were greater (data not presented), which is consistent with previous studies (Botton \& Loveland 1989). Importantly, the fraction of stranded crabs was not higher on nesting habitat inshore of farm gear (Fig. 5).

The density of crab eggs washed up in the wrack zone was unevenly distributed throughout the sur- veyed region of the Cape Shore. Washed up eggs were observed most frequently in the central portion of the survey area, and were not highly concentrated in the area of farms. Once eggs are resuspended from nests by wave action or other means, they are passively dispersed on waves and wind-driven currents (Smith et al. 2002) and tend to accumulate at concentrating features such as sand spits and jetties (Botton et al. 1994). Thus, the spatial pattern of egg concentration in the wrack line observed here does not necessarily reflect where concentrations of spawning females are coming ashore. Considering that $20 \%$ of the surficial eggs on the entire beach are found in the uppermost wrack line (Nordstrom et al. 2006), the spatial patterns of eggs in the wrack line should be a good relative predictor of the best shorebird foraging habitat within the survey region.

In general, more eggs are available to birds in the swash zone on a rising tide than are available remaining on the beach; therefore, active foraging in the swash zone during high, rising tides may provide the best foraging opportunities, and counts of eggs remaining on the beach may underestimate the absolute foraging opportunities (Nordstrom et al. 2006). Likewise, the distribution of available eggs baywide varies, with the highest densities of resuspended eggs found upbay in the areas of Sea Breeze on the New Jersey side of the bay, and Kitts Hummock and North Bowers on the Delaware side (Smith et al. 2002). Our surveys showed no evidence that farms interfere with the ability of spawning crabs to reach nest sites, and that optimal horseshoe crab egg-foraging opportunities for shorebirds are not coincident with farm locations.

Acknowledgements. We thank the field crew that helped count crabs and eggs at all hours of day and night: $M$. Acquafredda, S. Borsetti, B. Campbell, B. Cerione, M. Danihel, B. Dixon, E. Gilardi, J. Gius, F. Klie, H. Lehmann, L. O'Neil, N. Pray, B. Schum, J. Shinn, and M. Whiteside. Beach segments used for egg counts were established as part of the New Jersey Sea Grant project 'Identifying the Impacts of Commercial Oyster Aquaculture on Foraging Behavior of Red Knots in Delaware Bay.' Some crab stranding data reported here were collected concurrent with participation in the Wetlands Institute citizen science program, Return The Favor program, and we appreciate the training provided and important work they continue to do. We are grateful for the continued cooperation of the oyster farmers of Delaware Bay who allow us access to their farms. Thoughtful comments from 3 anonymous reviewers improved an earlier draft of the manuscript. This work was partially supported by the USDA National Institute of Food and Agriculture Hatch project accession numbers 1002345 and 1009201 through the New Jersey Agricultural Experiment Station, Hatch projects NJ32115 and NJ32114. 


\section{LITERATURE CITED}

Botton ML, Loveland RE (1989) Reproductive risk: high mortality associated with spawning horseshoe crabs (Limulus polyphemus) in Delaware Bay, USA. Mar Biol 101: 143-151

Botton ML, Loveland RE, Jacobsen TR (1988) Beach erosion and geochemical factors: influence on spawning success of horseshoe crabs (Limulus polyphemus) in Delaware Bay. Mar Biol 99:325-332

*Botton ML, Loveland RE, Jacobsen TR (1994) Site selection by migratory shorebirds in Delaware Bay, and its relationship to beach characteristics and abundance of horseshoe crab (Limulus polyphemus) eggs. Auk 111:605-616

Burger J, Howe MA, Hahn C, Chase J (1977) Effects of tidal cycles on habitat selection and habitat partitioning by migrating shorebirds. Auk 94:743-758

Burger J, Niles L, Clark KE (1997) Importance of beach, mudflat and marsh habitats to migrant shorebirds on Delaware Bay. Biol Conserv 79:283-292

Calvo LM (2017) New Jersey shellfish aquaculture situation and outlook report 2015 production year. New Jersey Sea Grant Publication NJSG-17-912

Castro G, Myers JP (1993) Shorebird predation on eggs of horseshoe crabs during spring stopover on Delaware Bay. Auk 110:927-930

* Clark KE, Niles LJ, Burger J (1993) Abundance and distribution of migrant shorebirds in Delaware Bay. Condor 95: 694-705

Dégremont L, Garcia C, Allen SK Jr (2015) Genetic improvement for disease resistance in oysters: a review. J Invertebr Pathol 131:226-241

Dumbauld BR, Ruesink JL, Rumrill SS (2009) The ecological role of bivalve shellfish aquaculture in the estuarine environment: a review with application to oyster and clam culture in the West Coast (USA) estuaries. Aquaculture 290:196-223

FAO (Food and Agriculture Organization of the United Nations) (2016) The state of world fisheries and aquaculture 2016. Contributing to food security and nutrition for all. FAO, Rome

Ford SE (1997) History and present status of molluscan shellfisheries from Barnegat Bay to Delaware Bay. In: MacKenzie CL, Burrell VG, Rosenfield A, Hobart WL (eds) The history, present condition, and future of the molluscan fisheries of North and Central America and Europe, Vol 1: North America. Tech Rep. U.S. Department of Commerce, NOAA, NMFS, Seattle, WA, p 119-140

Godet L, Toupoint N, Fournier J, Le Mao P, Retière C, Olivier F (2009) Clam farmers and oystercatchers: effects of the degradation of Lanice conchilega beds by shellfish farming on the spatial distribution of shorebirds. Mar Pollut Bull 58:589-595

Haramis GM, Link WA, Osenton PC, Carter DB and others (2007) Stable isotope and pen feeding trial studies confirm the value of horseshoe crab Limulus polyphemus eggs to spring migrant shorebirds in Delaware Bay.

Editorial responsibility: Megan La Peyre,

Baton Rouge, Louisiana, USA
J Avian Biol 38:367-376

Kraeuter JN, Fegley SR (1994) Vertical disturbance of sediments by horseshoe crabs (Limulus polyphemus) during their spawning season. Estuaries 17:288-294

Lathrop RGJ, Allen M, Love A (2006) Mapping and assessing critical horseshoe crab spawning habitats of Delaware Bay. Walton Center For Remote Sensing and Spatial Analysis, Rutgers University, New Brunswick, NJ

Loveland RE, Botton ML (2015) Sea level rise in Delaware Bay, USA: adaptations of spawning horseshoe crabs (Limulus polyphemus) to the glacial past, and the rapidly changing shoreline of the Bay. In: Carmichael RH, Botton ML, Shin PKS, Cheung SG (eds) Changing global perspectives on horseshoe crab biology, conservation and management. Springer, New York, NY, p 41-64

Morrison RIG, Hobson KA (2004) Use of body stores in shorebirds after arrival on high-Arctic breeding grounds. Auk 121:333-344

Newell RIE (2004) Ecosystem influences of natural and cultivated populations of suspension-feeding bivalve molluscs: a review. J Shellfish Res 23:51-61

Nordstrom KF, Jackson NL, Smith DR, Weber RG (2006) Transport of horseshoe crab eggs by waves and swash on an estuarine beach: implications for foraging shorebirds. Estuar Coast Shelf Sci 70:438-448

Rose JM, Bricker SB, Ferreira JG (2015) Comparative analysis of modeled nitrogen removal by shellfish farms. Mar Pollut Bull 91:185-190

Roycroft D, Kelly TC, Lewis LJ (2004) Birds, seals and the suspension culture of mussels in Bantry Bay, a nonseaduck area in Southwest Ireland. Estuar Coast Shelf Sci 61:703-712

Shumway SE, Davis C, Downey R, Karney R and others (2003) Shellfish aquaculture-in praise of sustainable economies and environments. World Aquacult 34:8-10

Kmith DR (2007) Effect of horseshoe crab spawning density on nest disturbance and exhumation of eggs: a simulation study. Estuaries Coasts 30:287-295

Smith DR, Pooler PS, Loveland RE, Botton ML, Michels SF, Weber RG, Carter DB (2002) Horseshoe crab (Limulus polyphemus) reproductive activity on Delaware Bay beaches: interactions with beach characteristics. J Coast Res 18:730-740

* Smith DR, Brockmann HJ, Beekey MA, King TL, Millard MJ, Zaldívar-Rae J (2017) Conservation status of the American horseshoe crab, (Limulus polyphemus): a regional assessment. Rev Fish Biol Fish 27:135-175

Walsh WL, Powposki R, Schrading E (2016) Biological opinion on the effects of existing and expanded structural aquaculture of native bivalves in Delaware Bay, Middle and Lower Townships, Cape May County, New Jersey on the federally listed red knot (Calidris canutus rufa). US Fish and Wildlife Service, New Jersey Field Office, Galloway, NJ

兴Žydelis R, Esler D, Kirk M, Boyd SW (2009) Effects of offbottom shellfish aquaculture on winter habitat use by molluscivorous sea ducks. Aquat Conserv 19:34-42

Submitted: February 20, 2017; Accepted: May 5, 2017

Proofs received from author(s): June 13, 2017 